\title{
Plasma density over Svalbard during the ISBJØRN campaign
}

\author{
C. M. Hall ${ }^{1}$, A. P. van Eyken ${ }^{2}$, K. R. Svenes ${ }^{3}$ \\ ${ }^{1}$ Department of Physics, University of Tromsø, N-9037 Tromsø, Norway \\ ${ }^{2}$ EISCAT Scientific Association, N-9170 Longyearbyen, Norway \\ ${ }^{3}$ Norwegian Defence Research Establishment, P.O. Box 25, N-2027 Kjeller, Norway
}

Received: 8 March 1999 / Revised: 7 September 1999 / Accepted: 10 September 1999

\begin{abstract}
In 1997, reliable operation of the EISCAT Svalbard Radar (ESR) was achieved and a rocket launching facility at $\mathrm{Ny}$ Ålesund on Svalbard $\left(79^{\circ} \mathrm{N}\right.$, $12^{\circ}$ E) (SVALRAK) was established. On 20 November, 1977, the first instrumented payload was launched from SVALRAK. Although the payload configuration had been flown many times previously from Andøya Rocket Range on the Norwegian mainland, this presented an unprecedented in situ determination of positive ion density over Svalbard. Simultaneously, ESR measured similar density profiles but in a higher altitude regime. We have combined the ESR measurements with ionosonde data to establish a calibration and subsequently combined the ground-based and in situ determined profiles to give a composite positive ion density profile from the mesosphere to the thermosphere.
\end{abstract}

Key words: Ionosphere (polar ionosphere; instruments and techniques)

\section{Introduction}

Until the end of 1997, the instrumentation on Svalbard $\left(80^{\circ} \mathrm{N}, 16^{\circ} \mathrm{E}\right)$ has not been adequate for the reliable and regular measurement of plasma density in the lower ionosphere. The EISCAT Svalbard Radar (Wannberg et al., 1997) has been troubled by two problems: (1) above E-region heights, the incoherent scatter spectra have exhibited anomalous behaviour relative to those obtained from similar instruments at lower latitude; (2) in the lower thermosphere and below measurements have been impeded by "clutter" or interference (the exact cause being unclear at the time of writing). Here, we attempt to circumvent these problems by combining

Correspondence to: C. M. Hall, e-mail: chris.hall@hys.uit.no incoherent scatter measurements with those of an ionosonde and rocket-borne positive ion probe. This kind of combination of instrumentation has been presented earlier by Hall et al. (1985) but for data from the north of Norway. The period we shall examine is the evening of the 20 November, 1997, although we shall briefly review the state of the ionosphere on the previous day.

The ISBJØRN I payload was flown on 20 November at 1732 UT and successful measurements were made in the height interval 50-71 km (Thrane et al., this issue). The positive ion probe (Blix et al., 1990), as the name suggests, determines the positive ion density, and this should not be confused with the electron density. In particular, at the time of year we shall present data from here, there is a strong likelihood that there was a significant negative ion content at least up to the upper mesosphere. The ESR system was directed at low elevation $\left(45^{\circ}\right)$ and scanned in azimuth. The pointing directions were $265^{\circ}, 270^{\circ}, 285^{\circ}, 300^{\circ}, 315^{\circ}, 330^{\circ}$ and $345^{\circ}$ with a dwell time of $2 \mathrm{~min}$ at each position. It is important to be able to visualise the geometry of the combined experiment in order to assess the assumptions regarding homogeneity and stationarity that will be implicit in our conclusion. Figure 1 shows a 3-dimensional view: Svalbard is seen from the southwest with horizontal axes indicating distance in kilometers from ESR; the vertical axis indicates altitude in kilometers; the parabola indicates the measured trajectory of ISBJØRN I; the straight line extending from ESR is a typical beam (azimuth $300^{\circ}$ ) and is dotted in the region where clutter/interference makes measurements useless (see later); the dotted line on the ground indicates the footprint of the ESR beam. In Fig. 1, note that ESR measures at much longer ranges than indicated here, but we have chosen not to extend the plot upwards to the left for clarity. Figure 2 shows a plan view of the information in Fig. 1, and in particular, the points on the ESR beam where it intersects selected altitudes. Systems of the configuration of ISBJØRN I are usually expected to attain higher altitudes in which case one can 

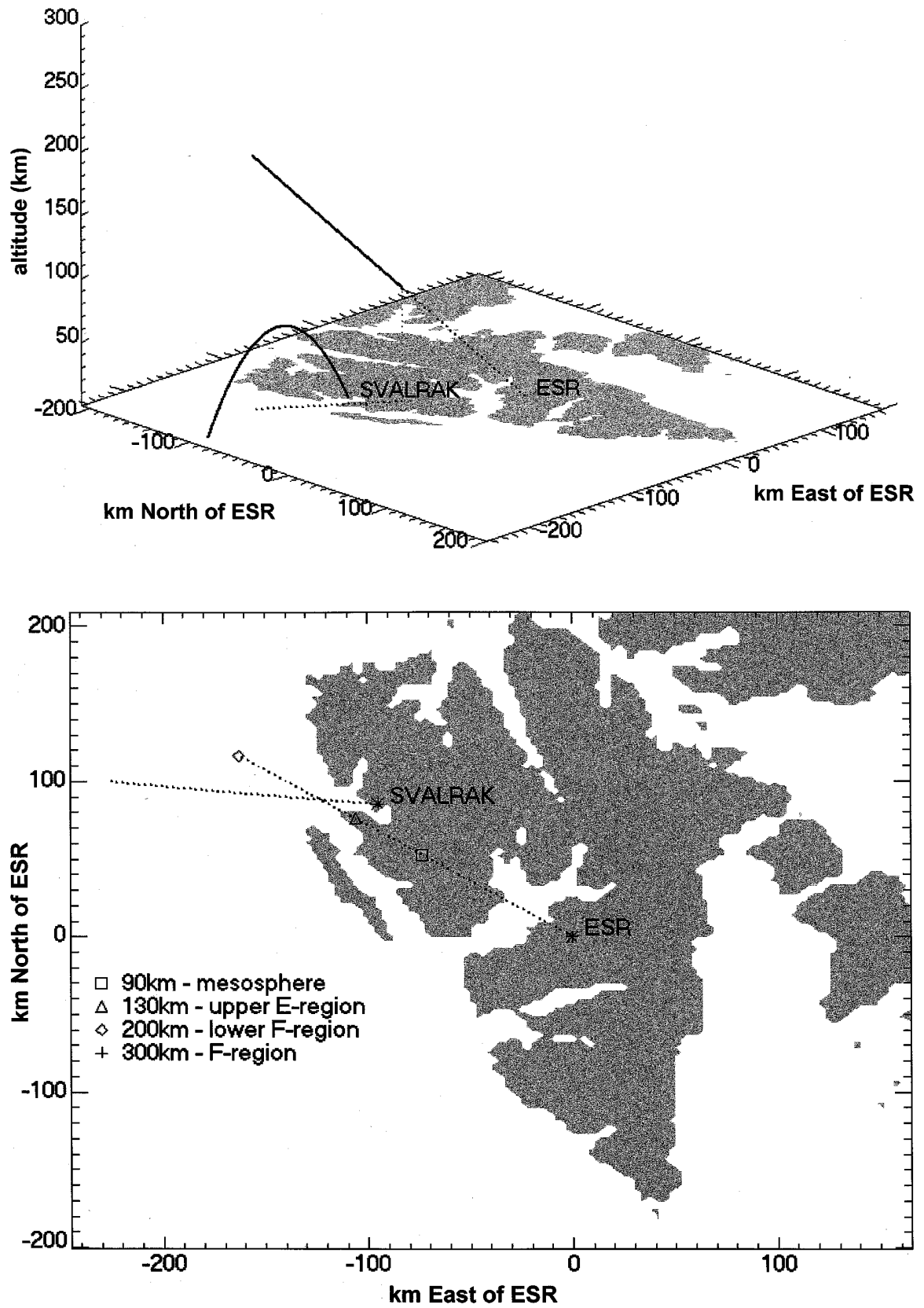

Fig. 1. Three-dimensional representation of the measurement geometry. The "floor" depicts Svalbard seen from the southwest with horizontal axes indicating distance in $\mathrm{km}$ from ESR. The vertical axis indicates altitude in $\mathrm{km}$; the parabola indicates the measured trajectory of ISBJØRN I. The straight line extending from ESR is a typical beam (azimuth $300^{\circ}$ ) and is dotted in the region where clutter/interference makes measurements useless (see text). The dotted line on the ground indicates the footprint of the ESR beam. Landmasses are grey; sea is left white
Fig. 2. Two-dimensional representation of the measurement geometry. This is essentially a plan view of the previous figure, but indicates intersections of the ESR beam with selected altitudes. The apogee of ISBJØRN I was $70 \mathrm{~km}$ and is this represented by the mid-point of the line extending west from SVALRAK see that the ESR measurement volume and the payload trajectory could be arranged to be very close. In our case, there was a spatial separation of around $100 \mathrm{~km}$ between the payload apogee and the lowest ESR volume. We shall see that conditions were geomagnetically quiet and that ESR failed to detect any substantial spatial structure in the plasma density during the period in question, and we shall use this as part of our justification for presenting a composite ion density profile. While such plasma density measurements are commonplace at, for example, the EISCAT mainland site $\left(69^{\circ} \mathrm{N}, 19^{\circ} \mathrm{E}\right)$, a database of such soundings does not, as yet, exist for Svalbard. Thus although this work will not present new physics, it is intended to contribute to establishing the status quo for the ionosphere at $80^{\circ} \mathrm{N}, 16^{\circ} \mathrm{E}$.

\section{ESR measurements}

While it is unfortunate that there are difficulties in measuring at low altitude (i.e. under $85 \mathrm{~km}$ as we shall see) with ESR and therefore determining true height profiles, pointing the radar at a $45^{\circ}$ elevation allows for a convenient portrayal of the results. In Figs. 3 and 4, we show the average electron density for the two periods of operation 1645-2300 UT on 19 November, 1997, and 1409-2010 UT on 20 November, 1997. The figures show plan views of the observed region with axes indicating horizontal distance from the ESR site. Since the elevation was very nearly $45^{\circ}$, the horizontal range from ESR is equal to the altitude. Stating that these are plots of electron density is, however, not quite true; equivalent electron densities have been calculated from 


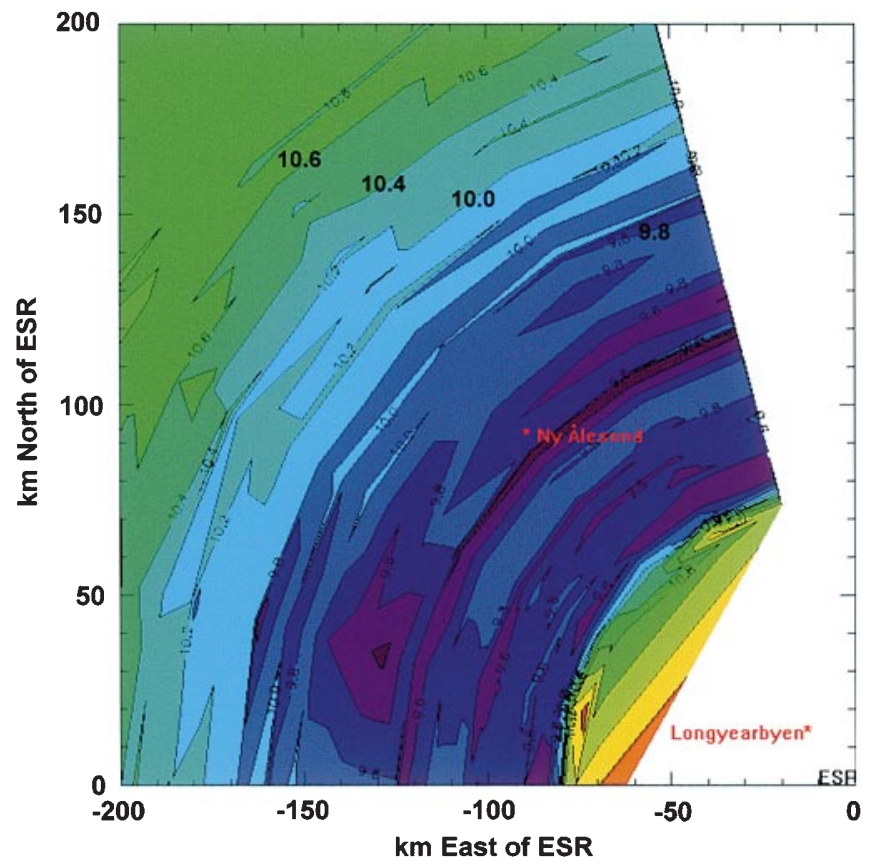

Fig. 3. Average electron density (or rather backscattered power calculated as electron density assuming scattering process is incoherent scatter) for 19 November, 1997. Axes denote horizontal distance from ESR. The radar operated at an elevation of $45^{\circ}$ such that the horizontal range on the plot is identical to the measurement altitude. Period of measurement was 1645-2300 UT. Contours are labelled in $\log _{10}\left(\right.$ electrons per $\left.\mathrm{m}^{3}\right)$

the backscattered power assuming the scattering process to be that of classical incoherent scatter (Lehtinen and Huuskonen, 1996). No account has been taken for possible presence of negative ions, a factor which may affect the signal especially below $95 \mathrm{~km}$. Little is known

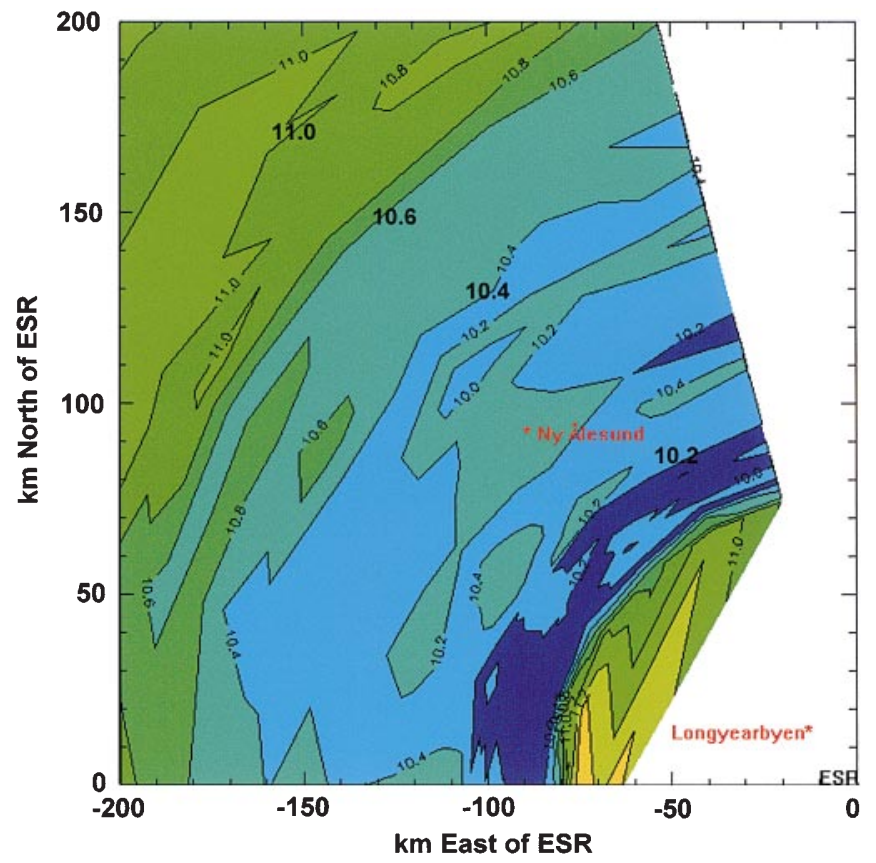

Fig. 4. As for Fig. 3 but for 20 November, 1997. Period of measurement was 1409-2010 UT of negative ion concentration at such high latitudes and this in itself would be a worthy continuation of this kind of investigation. More importantly, though, clutter or interference of some kind manifests itself below $85 \mathrm{~km}$ as can be clearly seen by the "trough" in density at this horizontal range; All signals/closer to the radar than $85 \mathrm{~km}$ must be construed as artefact. It is interesting to note that this $85 \mathrm{~km}$ limit is independent of azimuth and this raises the question as to whether ESR is indeed affected by ground clutter, which we would expect to exhibit azimuth dependence. In the figures, we have attempted to show the average nature of the degree of ionisation on these two days. Obviously short-term variations may have occurred which we have subsequently averaged out. In practice, some sporadic E had been observed on 19 November, but this was less prevalent on 20. The conditions otherwise varied little as can be confirmed by that absence of significant geomagnetic activity depicted by Fig. 5, in which the two panels show the magnetometer records (z-component) for Ny Ålesund (location of SVALRAK) for the two days in question. Furthermore, note that the ionosphere is not sunlit during this period. The solar $(10 \mathrm{~cm})$ flux was 86.5 on the launch day, with a mean $A p$ of 2 . Obviously, the individual soundings at 2 min resolution that have been averaged to construct Figs. 3 and 4 are also available, and in particular that nearest in time and space to ISBJØRN I; we shall defer presentation of this individual sounding until later.
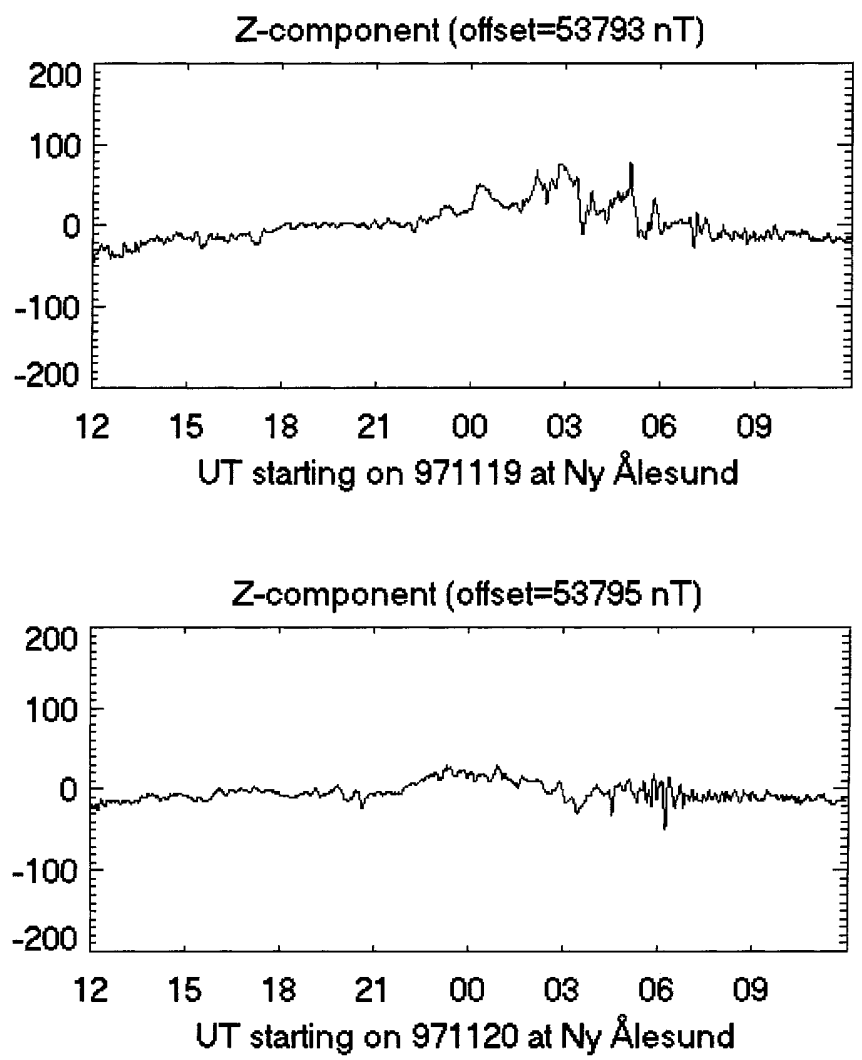

Fig. 5. Z-component magnetometer records for Ny Ålesund for 19 (top) and 20 (bottom) November, 1997. On each day, the record starts at 12 UT and extends for a $24-\mathrm{h}$ period 


\section{ISBJØRN measurements}

As described, the current flowing through the positive ion probe may be combined with the probe cross section to estimate the positive ion density. To illustrate the nature of this current we show the probe results in Fig. 6. Although plotted on a logarithmic scale (because the fluctuation amplitude tends to increase exponentially with height due to the increasing plasma density), we see that there is essentially a linear increase of positive ion

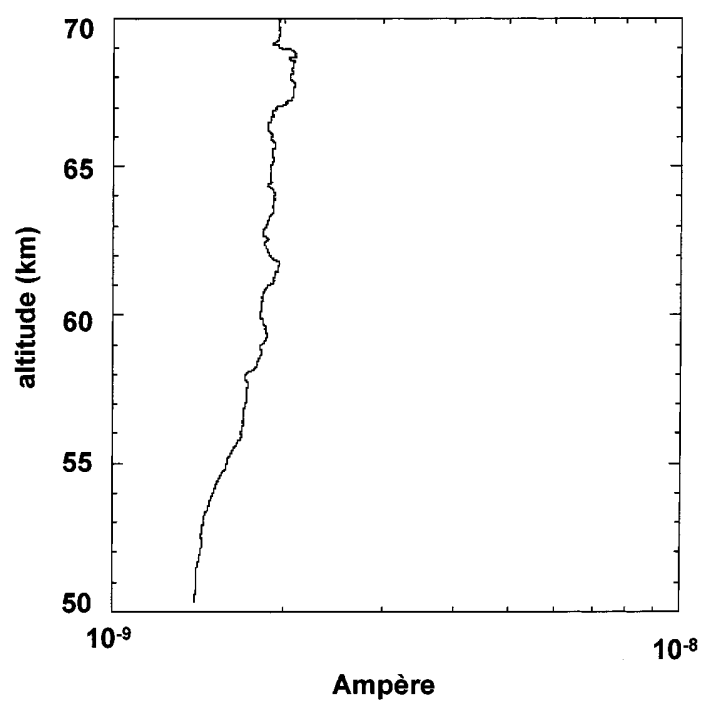

Fig. 6. Positive ion probe current for ISBJØRN I. The absolute units are unimportant; the general increase in current from 55 to $70 \mathrm{~km}$ corresponds to a linear increase in electron density from $2 \times 10^{8} \mathrm{~m}^{-3}$ to $7 \times 10^{8} \mathrm{~m}^{-3}$ density through the height range of the observation. The reliability of the calculation has been established by, for example, Hall et al. (1985). Had electron density been measured in situ by the same payload, the difference between this and the positive ion probe would have represented the negative ion density (in order to preserve quasi neutrality of the gas). The fluctuations in the signal may be used to determine turbulence parameters, but we shall not address this kind of physics here. The resulting positive ion densities were determined to be $2 \times 10^{9} \mathrm{~m}^{-3}$ at $50 \mathrm{~km}$ increasing almost linearly to $2.4 \times 10^{9} \mathrm{~m}^{-3}$ at $70 \mathrm{~km}$. The uncertainties due to instrumental noise and ion capture cross section amount to a factor 2 .

\section{Composite results}

While we have considerable confidence in the ion probe determinations of ion density, ESR calculations depend on a "system constant" to establish absolute values of plasma density. Furthermore, the nature of ESR operation, which entailed real-time transfer of plasma parameters onto the Internet in order to contribute to launch criteria for ISBJØRN I, precluded recording of uncertainties. We have attempted to circumvent this problem, however, by introducing ionosonde data (University of Leicester ionosonde) and scale the ESR profiles accordingly. Some minutes prior to launch, a sporadic E (Es) layer had been observed but as ISBJØRN I attained apogee this had faded and only a remnant remained. The ionogram subsequent to the ISBJØRN I flight is shown in Fig. 7. In the usual way (e.g. Hargreaves, 1992) we may convert the ionogram

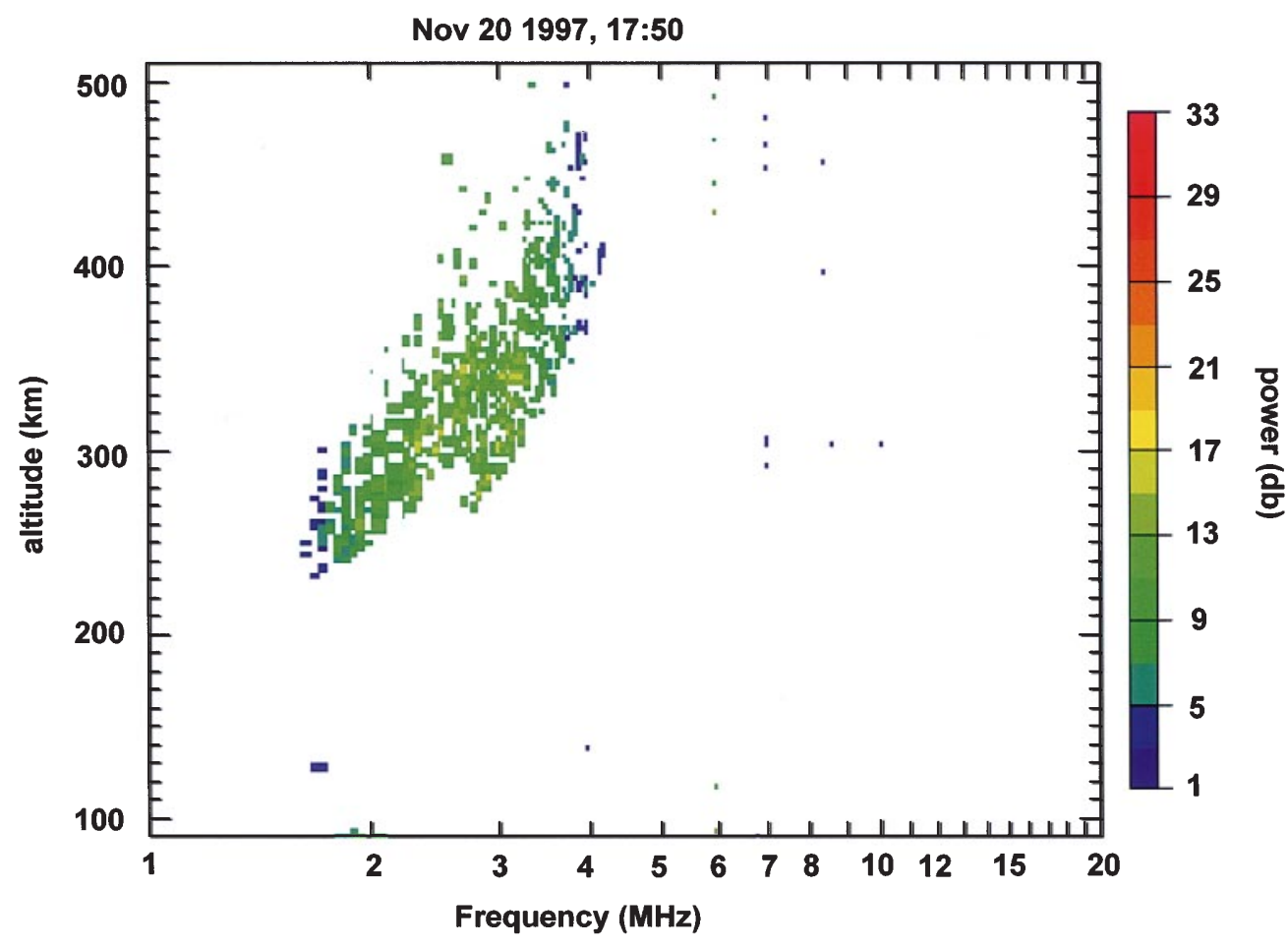

Fig. 7. Ionogram for $1750 \mathrm{UT}$ on 20 November, 1997. The small area of signal at about $125 \mathrm{~km}$ virtual height is considered to represent the remnants of an Es layer observed some 25 min earlier. The same feature is visible on the preceding ionogram at 1735 UT (not included here). The colour coding denotes signal strength 
critical frequencies to electron densities, which in turn indicate $5 \times 10^{10} \mathrm{~m}^{-3}$ at $260 \mathrm{~km}$ and $1.4 \times 10^{11} \mathrm{~m}^{-3}$ at $380 \mathrm{~km}$. Further to our discussion on the stationarity of the ionosphere during the evening of 20 November, we have noted little change in the F-region critical frequency, although a degree of variable Es was present.

Figure 8 depicts measurements from all three instruments on the same axes. The average of the factors required to scale the ESR plasma density profile to the ionosonde measurements was then determined, along with the standard deviation. The former was used to scale the ESR profile while the latter was used to determine a somewhat simplistic uncertainty. The identification of a minimum height of $85 \mathrm{~km}$ for useful observations by ESR at the time of the experiment via Figs. 4 and 5 and Hall (1997), leads to the rejection of data below $85 \mathrm{~km}$. The reader is asked to recall that the ESR measurements presented here were accumulated as a result of a telescience service to the launch of ISBJØRN I and future D-region investigation will entail a more stringent approach to error treatment. Furthermore, future combination of ionosonde soundings with ESR profiles will help to determine the ESR system constant with more confidence rendering the inclusion of ionosonde measurements unnecessary. Nevertheless, it is hoped that the results presented here are of use to future ESR operations as a reference. Combining the ionosonde data with the ESR profile in this way and interpolating between the ion probe profile and the incoherent profile we arrive at Fig. 9. The profile in Fig. 9 may either be interpreted as a positive ion density profile, or, if we assume no negative ions, an electron density profile. It is tempting to identify the ledge at around $90 \mathrm{~km}$ as the negative ion shelf, but the authors feel this is a dangerous interpretation with so

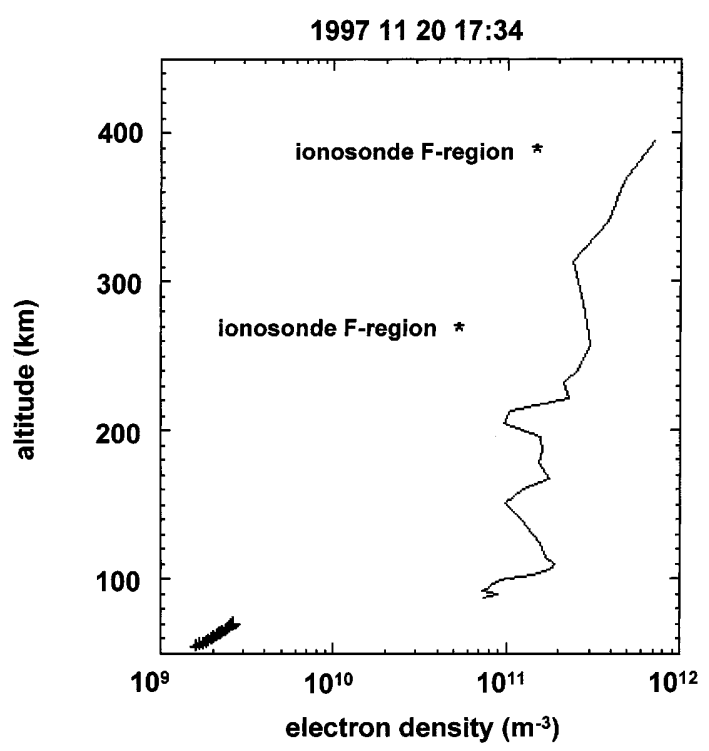

Fig. 8. All plasma density measurements for the launch of ISBJØRN I on 20 November, 1997. The solid line represents the ESR measurement; the dotted line represents the ISBJØRN I measurement and the two stars the ionosonde measurement

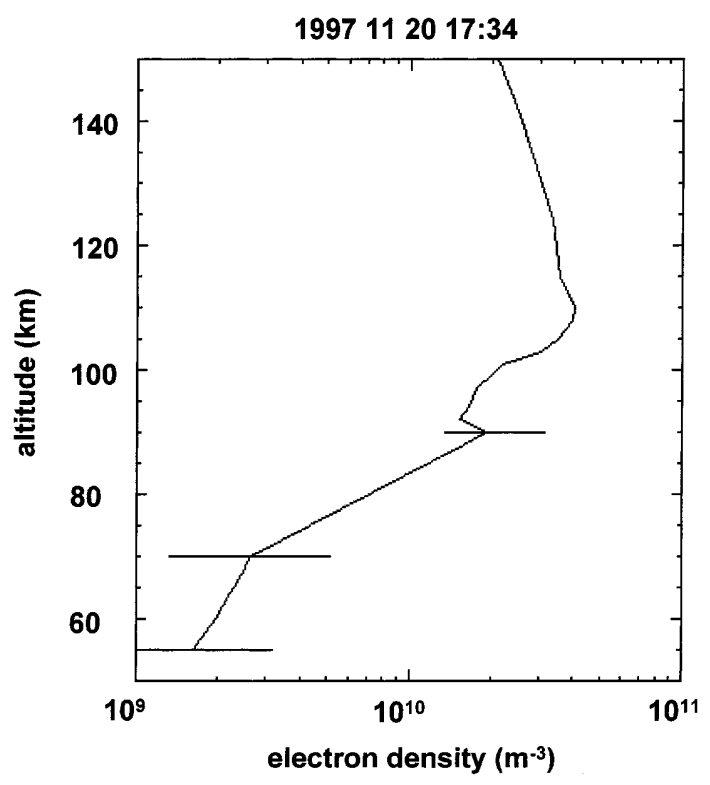

Fig. 9. Final composite plasma density profile for ISBJØRN I launch. See text for details

little data. It is conceivable that future investigation could establish negative ion density in ways similar to Hall et al. (1985), or Hall et al. (1998).

\section{Conclusion}

Despite not fully understood problems with ESR for measurements in the mesosphere, and the unexpectedly low apogee of the ISBJØRN I payload, we have determined a profile for positive ion density through the mesosphere and up to the F-region for the evening of 20 November, 1997, over Svalbard. We have determined, to some degree, the minimum measurement altitude for ESR at the time of writing and also the relation between electron densities indicated by the ESR standard analysis and ionosonde measurements. Although only an exploratory investigation has been reported here, it is of value for future measurements, both ground-based and in situ. The need to understand and alleviate the problems of low altitude ESR measurements have been identified, as has the need for combined in situ and ground-based measurements for mapping the negative ion presence in the mesosphere and lower thermosphere at high latitude.

Acknowledgements. The authors are indebted to the Director and staff of EISCAT for operating the facility and supplying the data. EISCAT is an International Association supported by Finland (SA), France (CNRS), the Federal Republic of Germany (MPG), Japan (NIPR), Norway (NFR), Sweden (NFR) and the United Kingdom (PPARC). The authors are also indebted to The University of Leicester for provision of ionosonde data. The authors thank the Magnetometer Group of the Auroral Observatory, Tromsø, Norway for provision of magnetometer data.

Topical Editor F. Vial thanks M. Friedrich and another referee for their help in evaluating this paper. 


\section{References}

Blix, T. A., E. V. Thrane, and Ø. Andreassen, In situ measurements of the fine-scale structure and turbulence in the mesosphere and lower thermosphere by means of electrostatic positive ion probes, J. Geophys. Res., 95, 5533-5548, 1990.

Hall, C., T. A. Blix, A. Brekke, M. Friedrich, T. L. Hansen, S. Kirkwood, J. Röttger, and E. V. Thrane, MAP/WINE electron density profiles in the D- and E-regions: a comparison of EISCAT, PRE and rocket data, Proc. 7th ESA Symposium (ESA SP-229), 279-284, 1985.

Hall, C., T. Devlin, A. Brekke, and J. K. Hargreaves, Negative ion to electron number density ratios from EISCAT mesospheric spectra, Phys Scripta, 37, 413-418, 1988.

Hall, C. M., Feasibility of using EISCAT Svalbard Radar (ESR) in conjunction with in situ measurements, Auroral Observatory
Technical Report 1/97, University of Tromsø, Tromsø, Norway, 1997.

Hargreaves, J. K., The solar terrestrial environment, Cambridge University Press, Cambridge, UK, 1992.

Lehtinen, M. S., and A. Huuskonen, General incoherent scatter analysis and GUISDAP, J. Atmos. Terr. Phys., 58, 435-452, 1996.

Thrane, E. V., T. A. Blix, and K. R. Svenes, Irregular structures observed in the nighttime polar D-region, Ann. Geophysicae, this issue, 1999.

Wannberg, U. G., I. Wolf, L.-G. Vanhainen, K. Koskenniemi, J. Röttger, M. Postila, J. Markkanen, R. Jacobsen, A. Stenberg, R. Larsen, S. Eliassen, S. Heck, and A. Huuskonen, The EISCAT Svalbard radar, a case study in modern incoherent scatter radar system design, Radio Sci., 32, 22832307, 1997. 